\title{
Determinants of Households' Adoption of Organic Pesticides for Lawns and Gardens
}

\author{
Lan Tran', Laura McCann'1, Dong Won Shin ${ }^{2}$ \\ ${ }^{1}$ Department of Agricultural and Applied Economics, University of Missouri, Columbia, MO, USA \\ ${ }^{2}$ Korea Environment Institute, Sejong, South Korea \\ Email:McCannL@missouri.edu
}

How to cite this paper: Tran, L., McCann, L. and Shin, D.W. (2020) Determinants of Households' Adoption of Organic Pesticides for Lawns and Gardens. Journal of Environmental Protection, 11, 269-298. https://doi.org/10.4236/jep.2020.114016

Received: February 14, 2020

Accepted: March 28, 2020

Published: March 31, 2020

Copyright (c) 2020 by author(s) and Scientific Research Publishing Inc. This work is licensed under the Creative Commons Attribution-NonCommercial International License (CC BY-NC 4.0). http://creativecommons.org/licenses/by-nc/4.0/

\begin{abstract}
This study investigates organic pesticide adoption in residential lawn care management, incorporating determinants based on a synthesis of multiple literatures. A mail survey using the Dillman method was conducted in Missouri in 2014 with a random sample of 2000 single-family households (44.1\% effective response rate). The data indicate an adoption rate of $17.7 \%$ for organic pesticides. This unique dataset also allows us to differentiate distinct non-adopters by familiarity with the practice as well as non-use of any pesticides. Multinomial logit regressions find environmental concerns, awareness of neighbor's opinions, and gardening behaviors as significant determinants. The effects on relative probability of being an adopter are large: 18 times more likely for people with serious environmental concerns or 5 times more likely for those spending more than 15 hours per month on lawn care.
\end{abstract}

\section{Keywords}

Adoption, Gardening, Organic Pesticides, Residential Lawn Care

\section{Introduction}

Lawns and gardens are popular in the United States; they are a source of enjoyment, a hobby and a source of home value. Homeowners in the U.S. spent about $\$ 47.8$ billion on lawn and garden purchases in 2016, with a record average expenditure of $\$ 503$ per household [1]. Pesticides are an important component; the home and garden sector accounted for about $6 \%$ of total U.S. pesticide usage in 2012 , valued at about $24 \%$ of conventional pesticide sales, compared to $66 \%$ by agriculture [2]. The highest expenditure was for insecticides, approximately $80 \%$ of the total amount spent by households. Pesticides are used to prevent, destroy, repel, or mitigate weeds, insects and other pests, and thus maintain the aesthetic 
value of lawns and gardens, as well as providing an ideal setting for outdoor recreation, entertainment and relaxation. However, the negative impacts of conventional pesticides include water pollution, biodiversity loss and exposures in children [3]. Therefore, there has been increasing interest in less toxic or organic pesticides or pesticide-free practices for use in residential lawn care management [4].

Potential strategies to reduce use of conventional pesticides are integrated pest management (IPM) (pesticide applications based on monitoring and thresholds), organic (monitoring and need-based organic and natural product applications), and non-use or untreated lawn care techniques. In fact, there are overlaps among these three approaches; using no pesticides or using organic pesticides can be part of IPM. Organic pesticides are appealing because of their less toxic and ready-to-use characteristics, although a few studies show that organic pesticides may have similar or even greater negative impacts than synthetic ones [5]. Homeowners can apply organic pesticides by themselves (following label instructions) or request professional services [6]. While there has been increasing interest in organic lawn management in the U.S., with widespread adoption of organic management practices in public spaces [4], the adoption rate of these practices for households is relatively low [7].

This leads to our research question: what factors prevent organic pesticide adoption and use in lawn care management regardless of the relative safety offered by these products? A fairly extensive literature examines adoption of best management practices (BMPs) by farmers. Typically, profitability, risk, environmental and health concerns, and some demographic factors are important determinants of BMP adoption [8]. For organic lawn care management, the story may be a bit different. Differences include the aesthetic value of a weed-free lawn to the homeowner and in the eyes of neighbors, the impact on the health of family members and pets, and the fact that gardening and lawn care are a hobby for some.

This paper explores determinants of household's adoption of organic pesticides in lawn care management using evidence from a mail survey in Missouri. A better understanding about factors affecting adoption from a homeowner perspective is necessary for gardeners, policy makers, environmentalists and companies. The existing literature on pesticides often focuses on agriculture rather than residential contexts, and on practices rather than products. On the other hand, the literature on organic products focuses on food consumption rather than use of items like cleaning or lawn-care products. This paper contributes to the literature on adoption of organic pesticide practices in lawn care management by synthesizing empirical studies on both organic consumption and organic farming/IPM in order to develop potential factors affecting adoption. In addition, comparing and contrasting adopters and types of non-adopters for organic pesticide practices provides deeper insights about the characteristics of each group. 


\section{Literature Review}

\subsection{Definitions of Organic Pesticides}

Merriam-Webster has definitions of organic that relate to organs, organisms, or carbon compounds, but the relevant one in this context is "of, relating to, yielding, or involving the use of food produced with the use of feed or fertilizer of plant or animal origin without employment of chemically formulated fertilizers, growth stimulants, antibiotics, or pesticides." The USDA National Organic Program only certifies agricultural products as organic if the products are produced using allowed substances in the National List of Allowed and Prohibited Substances, along with suitable production methods and third-party verification. However, there may be non-USDA certified organic products such as organic pesticides.

The National Pesticide Information Center (NPIC), a cooperative agreement between Oregon State University and the U.S. Environmental Protection Agency, provides an open list of commercial and homemade organic pesticides: bleach, pyrethrins, iron sulfate, copper sulfate, neem oil, vinegar, canola oil, salt, garlic, lemon grass, thyme, peppermint oil, etc., in which the overlaps between organic pesticides, biopesticides and minimum risk pesticides are acknowledged. The Organic Gardener's Handbook of Natural Insect and Disease Control [9] refers to organically acceptable pesticides as organic control products used in gardens that have three characteristics: derived from natural substances, less toxic to humans than synthetic pesticides, and quickly breaking down in the environment to harmless substances. Hence organic pesticides generally come with specific target pests, slow effectiveness, low residue levels with short persistence, and are thus likely to be safer than synthetic pesticides when their applications follow the label instructions carefully [9]. However, given the various definitions of organic pesticides, gardeners may interpret the term slightly differently.

\subsection{Factors Affecting Household's Adoption of Organic Pesticides}

The literature on residential adoption of organic pesticides used in lawn care is complex. Households buy organic pesticides to use as inputs in a home production activity like lawn care and then enjoy their lawn on a regular basis. The adoption of inputs like organic pesticides in home production can be related to organic agriculture or IMP production practices while the purchase of products like organic pesticides by end users may be related to organic consumption perspectives. Hence, the literature herein covers studies of both organic consumption and organic or IPM practices in agriculture. Most studies of household organic purchases examine consumers of food [10] [11] [12], or specific kinds of food like fresh vegetables or fruits (e.g. [13] [14] [15]), and drinks [16], but only few cases examine products for other purposes [17]. On the other hand, studying determinants of adoption of pesticide best management practices, work has primarily focused on farmers or agricultural producers rather than households [8] [18]. For a comprehensive literature review of organic pesticide adoption in lawn 
care from a household's perspective, this paper also examines other studies that explore demand or preferences of households for organic cleaning products [19] [20] or organic lawn care practices in general (e.g. [21] [22] [23] [24]). The following review integrates these literatures to develop a comprehensive set of potential determinants.

In empirical models, some socio-demographic characteristics have impacts on adoption. In the literature on organic purchases, for example, women may be more likely to buy organic products, because they express more concern for communal goals than men [25] or they want to protect their children from harmful effects of chemical products [20]. In the context of organic production, women are also likely to be organic producers for the same reasons [26].

Household income level consistently shows a positive effect on adoption of both organic purchases [11] [17] [27] and BMPs such as organic agriculture and IPM [8] [28] because this helps adopters overcome financial constraints related to organic products/inputs. We leave cost issues of organic pesticides to a discussion of price consciousness at the end of this review.

There are not such clear effects for household size, age, and education. Larger households may be less likely to purchase organic products [17], but it does not affect adoption of organic production. The number of children may have competing effects; it is highly correlated with household size, potentially reducing organic consumption, however having children may increase adoption due to health and safety concerns (as discussed below). Young people are more likely to buy organic food than older people [29] [30] and they might be more likely to adopt organic farming methods than older farmers [26], but the relationship between age and probability of BMP adoption is sometimes insignificant [31]. Similarly, higher educational level of homeowners tends to result in pesticide-free purchases [11] [27] [32] or use of organic practices [33], but the relationship is insignificant in other studies [26].

Environmental knowledge and attitudes usually are identified as critical drivers of organic adoption. Most empirical studies of organic consumption show positive effects on purchase intention of knowledge about organic products, awareness of threats from using synthetic pesticides, concerns about current quality of soil and water, or general attitudes of environmental protection (e.g. [11] [34] [35] [36]). However, the approach based on intended purchase is problematic because of the gap between behavior and attitudes toward organic products [37] or potential biases relating to environmentally friendly purchasing behavior [38]. A few studies show that environmental knowledge and attitudes do not positively affect actual purchase of organic products [11], and consumers might overestimate their organic purchases [39].

In the literature on organic farming, environmental knowledge and attitudes also play an important role in the adoption of organic and IPM practices [8] [40] [41]. However, the impacts on a farmer's adoption differ from a consumer's purchase of pesticide-free or lower pesticide products in terms of sensitivity. 
Consumers are likely to alter their behavior more easily than farmers do under awareness of serious environmental degradation, strict subjective norms, and high expectation of environment quality [41] [42]. The effect of knowledge on farmers' environmental behavior may also differ based on personal beliefs and emotions [43] lack of trust in information sources [44], and uncertainty and complexity [45]. Extending the concept of organic agriculture to lawn care management, households with more knowledge of lawn care are more likely to adopt BMPs [31].

In the literature, individually perceived benefits and costs associated with the innovation are the main factors affecting the adoption decision. While environmental knowledge and attitudes express public or general benefits, personal health and safety represent individual benefits. Organic products often are perceived as healthier or safer than conventional ones [35] [36] which leads to higher adoption of organic products to avoid health risks [46] [47]. This is related to why women, especially those with children, often show preferences for organic products, as noted in the demographic section. Many studies show that organic agriculture and IPM techniques help farmers reduce or avoid threats of chronic poisoning or cancer due to exposure to chemicals [48].

In the context of lawn care, health issues become important since household members experience a lawn treated with pesticides [3] [49]. Children are highly exposed to these chemicals because they often play in yards and pesticide residue may touch their skin. Hence, households who have children tend to adopt organic and natural pesticides rather than conventional ones [6] [50]. However, the number of children may negatively affect organic pesticide adoption as discussed above due to a possible interaction effect with average income, which implies more research is needed on this relationship [11] [51].

In addition to safety, expected quality of products can affect adoption. Past studies on organic purchase and organic production often view organic products as having better flavor [52] higher vitamins [36] as well as lower pesticide residues [53] which may lead to consumers buying organic rather than conventional products [54] [55] [56].

Regarding lawns, the concept of quality may include property value and aesthetic value (lawn appearance). In general, households who expect that organic lawn management may improve their property values are more likely to adopt this practice [28]. On the other hand, if the household prioritizes the appearance of the lawn, they might be more likely to purchase chemical pesticides, or hire commercial firms to effectively treat a problem such as grubs [6]. Perceptions of neighbors' attitudes about practices are considered in the adoption literature, with conflicting effects. From the neighbors' viewpoint, increased chemical pesticide use causes loss of biodiversity, landscape simplification and other harmful impacts [57], as a result, homeowners may adopt pesticide restriction techniques to reduce these negative impacts [40] [58]. On the other hand, a focus on the appearance of the lawn to comply with neighborhood norms may have the op- 
posite effect. Whether households employ a lawn care company for applying chemicals and pesticides depends on whether neighbors use them [28]. If people in a neighborhood tend to share the same aesthetic values regarding lawns and gardens, it may lead to favoring chemical pesticides which are perceived to be very effective. Hence, the effect of perceptions of neighbors' attitudes and practices on organic pesticide adoption is ambiguous: it is negative for yard or landscape appearance, and it is positive for environmentally friendly landscaping.

Individual preference that relates to enjoyment of yard work or gardening may affect the adoption of organic lawn management. For example, people who are more interested in gardening and able to do yard work tend to adopt alternative lawn care practices [22] because they may be more aware of, and gain more utility from using BMPs.

While safety and high quality or enjoyment of an organic lawn delivers benefits to households, the cost of organic products or methods presents a barrier to their adoption. Consumers often perceive organic products as expensive compared to conventional ones, which implies price negatively affects organic purchases [35] [36]. For households, commercial lawn management is the most expensive, followed by homeowner use of synthetic pesticides, and IPM or organic lawn management, which may include homemade organic pesticides [6]. Using no products obviously has no out-of-pocket costs. However, cost needs to be considered along with the associated quality or outcome. In the context of agriculture, the total cost of IPM or organic practices can potentially be lower, although farmers may substitute additional labor. Availability of cheap labor relative to pesticide cost may positively affect adoption of organic agriculture [59].

Besides cost issues, convenience has been considered a barrier to organic adoption. The concept of convenience refers to the amount of time involved with new practices. Studies found that consumers did not switch to organic food products due to convenience reasons like availability of organic products [35] or search time [60]. However, the implementation of USDA's national organic labeling standards in 2002 has helped to address these issues by providing quality assurance for organic foods [61]. Additionally, since 2006, the "Walmart effect" on the organic product market alleviated convenience issues [12] [62]. Regarding organic production, convenience may be related to availability of labor [59] or other inputs. Lawn care and pesticide use can be analyzed in the household production-consumption model of Becker (1965) [63]. In this model, the indirect utility of the household decreases with chemical pesticide use, but increases with leisure hours. Hence, time scarcity may negatively affect the adoption of organic lawn products.

Organic pesticides are potential replacements for conventional ones for residential use because of their safer yet ready-to-use characteristics. However, the household adoption rate of organic pesticides is currently low. By merging the literatures of organic consumption, organic farming as well as IPM practices, and lawn care management practices, this paper extracts hypotheses for poten- 
tial determinants of organic pesticide adoption in lawn care from the household's perspective as summarized in Table 1. Demographic variables like female gender and higher income level show positive effects on organic adoption while the effects of age and education are less robust. Environmental knowledge and attitudes, personal safety, and enjoyment of gardening may positively affect the use of organic pesticides while yard appearance/neighborhood norms and time scarcity have potentially negative impacts on adoption. There are various combinations of those attributes or dimensions, leading to difficulties in the classification of adopters for organic pesticides. There exist gaps in the literature regarding the role of children, perception of neighborhood attitudes, convenience, and knowledge on residential organic pesticide adoption.

\section{Conceptual Framework}

The study employs a discrete choice framework to examine determinants of organic pesticide adoption from the household perspective. For simplicity, household decisions are considered as individual choices as is usual in adoption studies. We thus ignore intra-household factors that may affect household decisions. Rogers (1962) provided a foundation for understanding adoption and diffusion of innovations. Adoption is an individual choice of accepting or rejecting an innovation that can be an object, technology, practice, etc., perceived as new to potential adopters [64] [65]. In this study, the innovation is use of organic pesticides in lawn care.

Table 1. Hypothesized effects on organic pesticide adoption.

\begin{tabular}{ccc}
\hline Factor & Organic consumption & Organic agriculture/ IPM \\
\hline Demographic variables & $(+)$ & $(+)$ \\
Younger age & + & + \\
Female & $(+)$ & $(+)$ \\
Higher education & + & + \\
Higher income & - & - \\
Larger household & + & $(+)$ \\
Environmental knowledge/attitudes & + & + \\
Personal health and safety concern & $(+)$ & \\
Having children & & + \\
Lawn quality & & + \\
Yard appearance & & - \\
Enjoyment & & - \\
Perceptions of neighborhood attitudes & $+/-$ & - \\
Price consciousness & - &
\end{tabular}

Note: $(+)$ or $(-)$ means the signs are insignificant in some studies; $+/-$ means the sign is indeterminant, for example neighbor's environmental concern $(+)$ or expectations of aesthetic value $(-)$ 
Discrete choice models can be derived from a utility maximization approach. Depending on whether use or non-use of the organic pesticide delivers greater utility (indirect utility value), households decide to be adopters or non-adopters. This paper uses a random utility-based discrete choice model (RUM), which includes stochastic or latent attributes of alternatives and individual characteristics [66], and has several advantages. First, the model can cover some components of preferences, which are unobservable to the researcher [67] [68]. Second, the RUM has a firm foundation in economics [69]. Another advantage is that the derived logit model is easily tractable with good empirical performance [66] [70].

The indirect utility of a typical RUM can be approximated by an appropriate linear function of observed characteristics of the alternatives, the individual, and the economic environment, and random error representing unobserved factors [71]. For multiple discrete choices, we have a set of random utilities associated with corresponding alternative choices for an individual. The derived logit model, also known as a multinomial logit model (MNL), is widely used to predict the probability or likelihood of the choice that yields the greatest utility among alternatives given a set of observed characteristics hypothesized to affect perceived utility. Specifically, MNL models require that random errors in the RUM are independently distributed and follow type 1 extreme value or log-Weibull distribution for a closed form likelihood expression of the integration [71]. Another important assumption of MNL models is the axiom of independence from irrelevant alternatives (IIA) [67]. The IIA assumption is to model individual choice probabilities and this can be tested by the Hausman-McFadden test or the Small-Hsiao test. Maximum likelihood estimation (MLE) is considered to be the most common method to estimate MNL models [66]. Estimation of the MNL model provides estimates of parameters or weights of observed characteristics used in the RUM [71]. Based on the results of the model, specific hypotheses extracted from the literature review are tested.

The main interest of this study is to examine the effects of environmental knowledge and attitudes, importance of neighbors, health concerns, and lawn care behaviors on a household's organic pesticide adoption decision. We hypothesize that pro-environmental attitudes positively affect adoption. Specifically, households who care more about the environment are more likely to adopt organic pesticides than conventional ones. This effect may be less for residents not applying any pesticides to their lawns. We also expect that households with more knowledge about the environment, and who are more familiar with organic pesticides will be more likely to be adopters. However, the importance given to the opinions of neighbors may negatively affect adoption; if it is important to them that their neighbors think they have a nice lawn they will prioritize aesthetic values over environmental ones.

Based on the previous literature, we assume that families with young children have more health concerns regarding the safety of pesticides applied to their 
lawns. Given this assumption, we predict a positive effect of young children on adoption of organic pesticides. Other demographic variables are included as controls.

Gardening behavior is expected to influence households' adoption choices because this relates to personal preferences. In this study, dimensions of lawn care behavior are conceptualized by time spent on lawn care and use of professional services for pest control. People often spend more time on yardwork if they enjoy gardening, and thus are expected to be more likely to be aware of and adopt environmentally friendly practices. On the other hand, households who use professional services for pest control will be less likely to adopt organic pesticides.

\section{Empirical Model and Data}

\subsection{Empirical Model}

We build a multinomial logit model to test our hypotheses of organic pesticide adoption using a sample of households obtained by the 2014 Hinkson Creek Household Survey. The survey was mailed to single-family detached homes in Columbia, Missouri using a random sample of 2000 residences provided by Survey Sampling International. The Dillman method was used with four waves of contact: a postcard notice, a cover letter and survey packet, a reminder postcard, and a final complete survey packet. The person most responsible for gardening was asked to respond the questionnaire. After removing invalid addresses, deceased residents, and those without yards, there were 1773 potential respondents. We received 783 completed surveys resulting in an effective response rate of $44.1 \%$.

The MNL model uses variables constructed from the survey results. Assuming revealed preferences of decision makers for conservation practices [72], the dependent variables related to the respondent's knowledge/experience of using organic pesticides. The choices included "Not applicable", "Never heard of it and not using it" (Never heard), "Somewhat familiar with it but not using it" (Know somewhat), "Know how to use it but not using it" (Know well), and "Currently use it" (Adopter). We do not eliminate "Not applicable" because this choice accounts for a substantial number of observations, 184 respondents, and it may imply various latent possibilities for not adopting organic pesticides, including: not using any pesticides, no availability of necessary organic pesticides, using professional pest control companies, etc. Of these 184 "Not applicable" cases, there are 61 residents who did not use professional services for pest control, never apply fertilizers to their lawns, and said "not applicable" for reading and following pesticide application instructions for their yards or gardens. Given these responses, we assume that these 61 households did not use any pesticides at all for their lawns. Thus, we put these non-adopters into a separate group called "Not using any pesticides" to distinguish them from other "Not applicable" non-adopters. In this way, the dataset enables us to differentiate five distinct 
types of non-adopters in the context of the MNL model.

Explanatory variables of the model describe observable attributes affecting the choice outcome and they are defined based on respondents' answers. We operationalize these variables to employ them in the MNL model. For seriousness of environmental concerns regarding locally excessive use of pesticides, the survey responses included: "not a problem", "slight problem", "moderate problem", "severe problem", and "don't know," accounting for 19, 130, 276, 221, and 109 cases, respectively. We combine the first two categories into "not or slight problem" and use it as the base category. Agreement with the statement "It is important that my neighbors think I have a nice lawn" was assessed using a five-point Likert scale, from "strongly disagree" to "strongly agree". There were 61, 159, 251,257 , and 24 respondents for the respective categories. We merge "strongly disagree" and "disagree" into a disagree category, and similarly form an agree category, while keeping "neutral" answers separate. To get at health concerns of pesticide use on young children we created a dummy variable for whether the household has at least one child under age 12.

Time spent gardening, one of two aspects of gardening behavior, was measured by four time-interval categories: "0 - 5 hours", "6 - 10 hours" (the base category), "11 - 15 hours", and "more than 15 hours." We keep this variable as described in the survey to represent household's monthly hours spent on gardening and lawn care during the growing season, which may indicate preferences for gardening as a hobby. We also examined the professional lawn care services used by the household; the options included: "No", "Yes, just for mowing", "Yes, for mowing and fertilizing", "Yes, just for fertilizing and pest control", and "Yes, for mowing, fertilizing, and pest control' accounting for 522, 50, 36, 105, and 40 cases, respectively. We constructed a dummy variable by combining the first three responses into "not using pest control services," while the last two responses became "using a pest control service."

To increase the explanatory power of the model, we added specific attributes of the background environment and demographic variables [71] [73]. The need for effective pest control is proxied by weed density in the lawn; we expect low weed density to be associated with organic pesticide adoption and for high weed density to be associated with non-adoption. Alternatively, this variable may represent previous use of effective synthetic pesticides in which case the effect on adoption would be opposite. In the dataset, the weed density measured by the average number of weeds per square yard is represented by five options: "None", "1 to 10 ", “11 to 40", “More than 40" weeds, and "Don't know" resulting in 50, $259,151,37$, and 254 cases, respectively. We combine the categories of "None" and " 1 to 10 " into "Less than 10" and use that as the base category.

For demographic variables, we choose gender, age, annual household income and educational attainment which theoretically affect the adoption choices in our model. (The presence of young children is included above.) Gender is a dummy variable with female as the base. The survey contained four age inter- 
vals: "18 - 30 years", "31 - 45 years", "46 - 60 years", and "Over 60 years" (the base category). Educational attainment consists of five possible categories: "Some formal schooling", "High school diploma or GED", "Some college or 2 year college degree", "4 year college degree", and "post-graduate degree" with 8 , $72,154,254$, and 265 cases, respectively. We combined the first two categories into a "High school or less" base category. Annual household income included five options: “less than $\$ 24,999$ ", “\$25,000 - $\$ 49,999$ ” (the base), “\$50,000 $\$ 74,999$ ", “\$75,000 - $\$ 99,999$ ”, and “ $\$ 100,000$ or more."

To sum up, the empirical MNL model is specified as follows:

$$
P\left(y_{i}=k\right)=\frac{\exp \left(x_{i} \beta_{k}\right)}{\sum_{j=1}^{6} \exp \left(x_{i} \beta_{j}\right)}
$$

The model takes a simple form of Luce model (e.g. [67] [71] to predict the

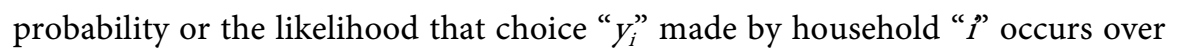
the sample of size " $n$." " $k$ " represents alternative organic pesticide adoption choices: "adopt", and five non-adopter alternatives: "never heard", "know somewhat", "know well", "not use any pesticides", and "other N/A." We can thus classify households as adopters and distinct types of non-adopters. Since we distinguish among various types of non-adopters, we use "adopters" as the base of the model, which differs from traditional adoption studies.

In the model, " $x$ " is a vector of explanatory variables from household " $i$ " responses while " $\beta$ " is vector of corresponding parameters in the model. Since all variables used categorical data, we choose a specific reference category for each variable for estimation and interpretation of the MNL model. In a base model, " $X$ " includes these variables: Seriousness of environmental concerns (base: not or slight problem), Importance of neighbors' perception of nice lawn (base: agree), Having at least one child under 12 (base: no), Monthly hours spent on lawn (base: 6 - 10 hours), Using professional pest control services (base: no), Weed density (base: less than 10 weeds per square yard), Male (base: Female), Age (base: above 60 years), Education (base: high school or less), Household income (base: $\$ 25,000$ - 49,000).

\subsection{Data Description}

Summary statistics for the data used for the regression model can be found in Table 2. These statistics are reported for the dataset as a whole as well as separately for adopters and different types of non-adopters. (Column percentages by each variable category sum to $100 \%$.) After removing missing values of the outcome (28 observations), the adoption rate for organic pesticides is $17.7 \%$ while non-adoption rates of "Never heard", "Know somewhat", "Know well", "Not using any pesticides", and "Other N/A" groups are 5.5\%, 28.8\%, 23.7\%, 8.0\%, and $16.3 \%$ respectively. Compared to the adoption rate of residential organic lawn care in Louisiana of $15.6 \%$ [7], the adoption rate in this sample is slight larger. 
Table 2. Summary statistics.

\begin{tabular}{|c|c|c|c|c|c|c|c|c|}
\hline \multirow[b]{2}{*}{ Variable } & \multicolumn{2}{|c|}{ Sample Proportions* } & \multirow[t]{2}{*}{ Adopters } & \multicolumn{5}{|c|}{ Non-Adopters } \\
\hline & Mean & Std. Dev. & & $\begin{array}{l}\text { Never } \\
\text { heard }\end{array}$ & $\begin{array}{c}\text { Know } \\
\text { somewhat }\end{array}$ & Know well & $\begin{array}{l}\text { Not using any } \\
\text { pesticides }\end{array}$ & $\begin{array}{l}\text { Other not } \\
\text { applicable }\end{array}$ \\
\hline Organic Pesticide Adoption & & & $17.7 \%$ & $5.5 \%$ & $28.8 \%$ & $23.7 \%$ & $8.0 \%$ & $16.3 \%$ \\
\hline \multicolumn{9}{|l|}{ Predictors } \\
\hline \multicolumn{9}{|c|}{ Seriousness of environmental concerns } \\
\hline Not or slight problem (base) & 0.197 & 0.014 & $9.8 \%$ & $26.2 \%$ & $23.4 \%$ & $18.0 \%$ & $13.1 \%$ & $27.6 \%$ \\
\hline Moderate problem & 0.366 & 0.018 & $37.6 \%$ & $35.7 \%$ & $38.5 \%$ & $39.9 \%$ & $23.0 \%$ & $34.1 \%$ \\
\hline Severe problem & 0.293 & 0.017 & $40.6 \%$ & $11.9 \%$ & $27.5 \%$ & $30.9 \%$ & $39.3 \%$ & $18.7 \%$ \\
\hline Don't know & 0.144 & 0.013 & $12.0 \%$ & $26.2 \%$ & $10.6 \%$ & $11.2 \%$ & $24.6 \%$ & $19.5 \%$ \\
\hline \multicolumn{9}{|c|}{ Neighbors opinion of lawn important } \\
\hline Disagree & 0.375 & 0.018 & $30.3 \%$ & $38.1 \%$ & $39.8 \%$ & $44.4 \%$ & $9.8 \%$ & $44.7 \%$ \\
\hline Neutral & 0.292 & 0.017 & $33.3 \%$ & $21.4 \%$ & $26.9 \%$ & $27.2 \%$ & $47.5 \%$ & $25.2 \%$ \\
\hline Agree (base) & 0.333 & 0.017 & $36.4 \%$ & $40.5 \%$ & $33.3 \%$ & $28.3 \%$ & $42.6 \%$ & $30.1 \%$ \\
\hline Have children under 12 & 0.242 & 0.016 & $19.4 \%$ & $29.3 \%$ & $25.1 \%$ & $27.5 \%$ & $26.7 \%$ & $19.8 \%$ \\
\hline \multicolumn{9}{|c|}{ Monthly hours spent on gardening/lawn } \\
\hline 0 - 5 hours & 0.195 & 0.014 & $9.8 \%$ & $26.2 \%$ & $18.1 \%$ & $14.0 \%$ & $37.3 \%$ & $29.8 \%$ \\
\hline $6-10$ hours (base) & 0.347 & 0.017 & $25.0 \%$ & $47.6 \%$ & $38.6 \%$ & $34.3 \%$ & $32.2 \%$ & $35.5 \%$ \\
\hline $11-15$ hours & 0.221 & 0.015 & $25.0 \%$ & $14.3 \%$ & $22.3 \%$ & $27.0 \%$ & $13.6 \%$ & $18.2 \%$ \\
\hline More than 15 hours & 0.237 & 0.016 & $40.2 \%$ & $11.9 \%$ & $20.9 \%$ & $24.7 \%$ & $16.9 \%$ & $16.5 \%$ \\
\hline Hire pest control services & 0.193 & 0.014 & $22.0 \%$ & $21.4 \%$ & $20.6 \%$ & $17.9 \%$ & $0.0 \%$ & $24.8 \%$ \\
\hline \multicolumn{9}{|l|}{$\underline{\text { Lawn attributes }}$} \\
\hline \multicolumn{9}{|c|}{ Number of weeds per square yard } \\
\hline$\leq 10$ weeds (base) & 0.411 & 0.018 & $45.4 \%$ & $38.1 \%$ & $38.2 \%$ & $45.8 \%$ & $26.2 \%$ & $43.4 \%$ \\
\hline $11-40$ weeds & 0.201 & 0.015 & $19.2 \%$ & $11.9 \%$ & $12.7 \%$ & $23.5 \%$ & $26.2 \%$ & $13.1 \%$ \\
\hline$>40$ weeds & 0.049 & 0.008 & $4.9 \%$ & $2.4 \%$ & $6.9 \%$ & $2.8 \%$ & $1.6 \%$ & $4.9 \%$ \\
\hline Don't know & 0.338 & 0.017 & $28.5 \%$ & $47.6 \%$ & $33.2 \%$ & $27.9 \%$ & $45.9 \%$ & $38.5 \%$ \\
\hline \multicolumn{9}{|l|}{ Demographic characteristics } \\
\hline Male & 0.632 & 0.018 & $57.1 \%$ & $66.7 \%$ & $68.1 \%$ & $67.4 \%$ & $45.9 \%$ & $62.8 \%$ \\
\hline \multicolumn{9}{|l|}{ Age } \\
\hline $18-30$ years & 0.085 & 0.010 & $4.5 \%$ & $9.5 \%$ & $9.7 \%$ & $6.2 \%$ & $14.8 \%$ & $10.7 \%$ \\
\hline $31-45$ years & 0.253 & 0.016 & $23.3 \%$ & $28.6 \%$ & $25.8 \%$ & $27.5 \%$ & $29.5 \%$ & $19.8 \%$ \\
\hline $46-60$ years & 0.307 & 0.017 & $29.3 \%$ & $33.3 \%$ & $33.6 \%$ & $27.0 \%$ & $29.5 \%$ & $32.2 \%$ \\
\hline$>60$ years $($ base $)$ & 0.355 & 0.017 & $42.9 \%$ & $28.6 \%$ & $30.9 \%$ & $39.3 \%$ & $26.2 \%$ & $37.2 \%$ \\
\hline \multicolumn{9}{|l|}{ Educational attainment } \\
\hline High school or less (base) & 0.106 & 0.011 & $7.5 \%$ & $9.8 \%$ & $10.1 \%$ & $10.6 \%$ & $8.2 \%$ & $16.5 \%$ \\
\hline 2 -year or some college & 0.205 & 0.015 & $23.3 \%$ & $22.0 \%$ & $18.0 \%$ & $22.2 \%$ & $23.0 \%$ & $17.4 \%$ \\
\hline
\end{tabular}




\section{Continued}

\begin{tabular}{|c|c|c|c|c|c|c|c|c|}
\hline 4-year college & 0.337 & 0.017 & $33.1 \%$ & $34.1 \%$ & $36.9 \%$ & $34.4 \%$ & $31.1 \%$ & $28.9 \%$ \\
\hline Post-graduate & 0.352 & 0.017 & $36.1 \%$ & $34.1 \%$ & $35.0 \%$ & $32.8 \%$ & $37.7 \%$ & $37.2 \%$ \\
\hline$\$ 0-\$ 24,999$ & 0.076 & 0.010 & $4.0 \%$ & $17.6 \%$ & $5.5 \%$ & $4.0 \%$ & $17.2 \%$ & $7.5 \%$ \\
\hline$\$ 25,000-\$ 49,999$ (base) & 0.201 & 0.015 & $21.6 \%$ & $23.5 \%$ & $15.6 \%$ & $21.6 \%$ & $31.0 \%$ & $25.2 \%$ \\
\hline$\$ 50,000-\$ 74,999$ & 0.264 & 0.017 & $28.8 \%$ & $14.7 \%$ & $26.6 \%$ & $25.3 \%$ & $27.6 \%$ & $28.0 \%$ \\
\hline$\$ 75,000-\$ 99,999$ & 0.172 & 0.014 & $14.4 \%$ & $23.5 \%$ & $19.6 \%$ & $17.6 \%$ & $15.5 \%$ & $14.0 \%$ \\
\hline$\$ 100,000$ and above & 0.287 & 0.017 & $31.2 \%$ & $20.6 \%$ & $32.7 \%$ & $32.9 \%$ & $8.6 \%$ & $25.2 \%$ \\
\hline
\end{tabular}

Note: For categorical variables, the fractions are defined on the domain $(0,1)$.

The summary statistics in Table 2 show that adopters look different from the sample as a whole in seriousness of environmental problems regarding pesticides, neighbor opinions of their lawn being important, and time spent gardening. There are also several noticeable differences across distinct types of non-adopters. For example, "severe" is the most common response regarding pesticide problems for adopters and for those who use no pesticides, $40 \%$, compared to $29 \%$ for the whole sample. Compared to the whole sample (38\%), a lower percentage of adopters (30\%) disagree that neighbors' opinions are important, but this difference masks the much lower level of disagreement among those not using any pesticides (10\%) and the much higher disagreement (over $44 \%)$ of non-adopter categories know well and other N/A. This data highlights the importance of distinguishing among types of non-adopters and separating those who use no pesticides from other responses. About $40 \%$ of adopters spent more than 15 hours per month gardening while the most common response overall was 6 - 10 hours. The most common response for those who don't use pesticides was 0 - 5 hours, which was the second most common for never heard and other N/A categories (26\% and 30\%). The weed question is also interesting; $28 \%$ of adopters didn't know how many weeds they had, but for those who had never heard of organic pesticides and those who don't use pesticides, over $45 \%$ didn't know. This may indicate that these non-adopters are more generally not interested in gardening and lawn care.

Demographic statistics indicate that adopters are somewhat less likely to be male than all non-adopter categories other than those who use no pesticides. They are also less likely to have young children. Adopters are older than the sample as a whole, especially compared to those who use no pesticides. Educational levels for adopters and those using no pesticides are fairly similar, but those who use no pesticides are much more likely to be in the lower income categories than adopters. Given the population for this dataset (those living in homes with yards), respondents being older, richer, and more educated than the relevant Census data is reasonable [73]. In Table 2, we also see the standard deviations of the sample averages are small: less than 0.02 and about $10 \%$ of the 
corresponding sample means. This implies the sample means are statistically robust, and thus the dataset is appropriate for further analyses of the determinants of organic pesticide adoption.

\section{Results and Discussion}

We begin this section by discussing the way the regression results are reported and interpreted. For our empirical MNL model where adopters are the base and distinct types of non-adopters represent alternatives, there are separate outcomes for each type of non-adopter category as if we independently estimated logistic regressions for each group of non-adopters compared to adopters. In other words, the model results include estimated coefficients, significance levels, and goodness-of-fit statistics for non-adopter types of "never heard", "know somewhat", "know well", "not use any pesticides", and "other N/A", compared to the base of adopters. Since all explanatory variables are categorical, a coefficient is interpreted as the difference in the logit or log-odds of being a specific type of non-adopter rather than an adopter, due to the effect of that response category versus the base category, all else equal. The exponential of an estimated coefficient can be interpreted as how many times more/less likely it is to be a specific non-adopter type versus an adopter of organic pesticide practices. A positive coefficient means the odds are greater than 1: the respondent is more likely to be a non-adopter than adopter if they chose that response category rather than the base category for that variable. A negative coefficient implies the respondent is less likely to be a non-adopter than an adopter based on that variable. Again, this differs from typical adoption studies; here, negative coefficients imply that variable positively affects adoption.

Regression results of the preferred model are reported in Table 3. In terms of goodness-of-fit of the MNL model, the McFadden pseudo $\mathrm{R}^{2}$ is $10.8 \%$ (the alternatives Nagelkerke or Cox \& Snell pseudo $\mathrm{R}^{2}$ are about $30 \%$ ). Since the model uses the MLE method to calculate estimates, the pseudo $\mathrm{R}^{2}$ implies a different interpretation from that of ordinary least squares (OLS), but in general, the higher the pseudo $\mathrm{R}^{2}$ value, the better the fit of the model. While the low pseudo $\mathrm{R}^{2}$ implies the model might be improved by adding more explanatory variables, it is acceptable relative to other empirical studies [73]. Moreover, the likelihood ratio test for the model is highly significant, $a$-level $=1 \%$ confirming that the model significantly predicts the likelihood of organic pesticide non-adoption.

From Table 3, we can see important variables in the model. Only statistically significant results are discussed. As expected, perceived seriousness of environmental problems related to pesticides affects adoption of organic pesticides. The estimated coefficients are negative, implying those who indicated "moderate problem" rather than the base "not or slight problem" are less likely to be non-adopters, or in other words, they tend to be adopters. If they indicated it is a "serious problem" they are less likely to be a non-adopter, except those who use no pesticides, and the effects are generally larger. For example, the estimate for 
Table 3. Multinomial logit regression results for the full model (Base: Adopters).

Independent Variables (Factors)

Non-Adopters

Never heard Know somewhat Know well No Pesticides Other N/A

Personal attitude measures

Environmental concerns (base: Not or slight problem)

Moderate problem

Serious problem

Don't know

$\begin{array}{lllll}-1.365^{* *} & -0.976^{* *} & -0.834^{*} & -1.413^{* *} & -1.492^{* * *} \\ -2.692^{* * *} & -1.227^{* * *} & -0.842^{*} & -0.819 & -2.039^{* * *} \\ -0.288 & -0.663 & -0.398 & -0.044 & -0.699\end{array}$

Neighbors' opinion of lawn important (base: Agree)

Disagree

$\begin{array}{lllll}-0.900 & -0.782^{* *} & -0.763^{* *} & 0.769 & -1.133^{* * *} \\ -0.198 & -0.509 & -0.633^{* *} & 1.039^{*} & -0.824^{* *}\end{array}$

Neutral

$-0.509$

$-0.633^{\star \star}$

$1.039^{*}$

$-0.824^{* \star}$

Having children under 12 (base: No children)

At least 1 child

0.49

0.095

0.188

0.357

0.019

\section{Gardening behaviors}

Monthly hours spent gardening (base: 6 - 10 hours)

\section{0 - 5 hours \\ $11-15$ hours}

More than 15 hours

\section{Pest control services hired (base: No)}

Use service

\section{$\underline{\text { Lawn attributes }}$}

Number of weeds per square yard (base: $<10$ weeds)

10 - 40 weeds

More than 40 weeds

Don't know

\section{$\underline{\text { Demographic characteristics }}$}

\section{Male}

Age (base: $>60$ years)

18 - 30 years

$31-45$ years

$46-60$ years

Educational attainment (base: High school or less)

Some college or 2-year college

4-year college

Post-graduate

Household income (base: $\$ 25,000$ - \$49,999)

$<\$ 24,999$

$\$ 50,000$ - $\$ 74,999$

$\begin{array}{ccccc}0.297 & 0.491 & 0.251 & 0.972^{\star *} & 0.085 \\ -15.790 & 0.710 & -0.546 & -1.232 & 0.388 \\ 0.711 & 0.457 & 0.097 & 0.944^{\star *} & 0.413 \\ & & & & \\ 0.522 & 0.436 & 0.433 & -0.278 & 0.358 \\ & & & & \\ 0.923 & 0.851 & 0.138 & 1.267^{\star} & 0.944 \\ 0.147 & 0.184 & 0.017 & 0.423 & -0.005 \\ 1.051^{\star} & 0.421 & -0.065 & 0.830^{\star} & 0.489\end{array}$

$\begin{array}{lllll}-0.500 & -1.094^{* *} & -0.878^{*} & -0.703 & -1.135^{\star *} \\ -0.121 & -0.409 & -0.616 & -0.061 & -0.710 \\ -0.151 & -0.640 & -0.790 & -0.046 & -0.540 \\ & & & & \\ 0.802 & -0.024 & 0.269 & 0.465 & -0.317 \\ -1.212^{\star} & -0.144 & -0.048 & -0.526 & -0.556\end{array}$




\begin{tabular}{|c|c|c|c|c|c|}
\hline \multicolumn{6}{|l|}{ Continued } \\
\hline$\$ 75,000-\$ 99,999$ & 0.014 & 0.312 & 0.309 & -0.207 & -0.503 \\
\hline$>\$ 100,000$ & $-1.360^{*}$ & -0.178 & 0.044 & $-1.530^{* *}$ & $-1.087^{\star *}$ \\
\hline Constant & 0.413 & $2.099^{* * *}$ & $2.179^{\star * *}$ & -0.482 & $2.793^{\star * *}$ \\
\hline \multicolumn{6}{|l|}{ Goodness-of-fit } \\
\hline $\mathrm{N}$ & & & 661 & & \\
\hline LR Chisquare (120) & & & 236.35 & & \\
\hline $\operatorname{Pr}(>$ Chisquare $)$ & & & $1.283 \mathrm{e}-09^{* * *}$ & & \\
\hline AIC & & & 2208.599 & & \\
\hline BIC & & & 2770.318 & & \\
\hline McFadden's Pseudo $\mathrm{R}^{2}$ & & & $10.8 \%$ & & \\
\hline Cox \& Snell Pseudo's $\mathrm{R}^{2}$ & & & $30.1 \%$ & & \\
\hline Nagelkerke's Pseudo ${ }^{2}$ & & & $30.1 \%$ & & \\
\hline
\end{tabular}

Notes: Superscripts ${ }^{\star},{ }^{* *}$ and ${ }^{* *}$ indicate statistical significance at the 10 percent, 5 percent and 1 percent levels, respectively.

"never heard" is the largest, at 2.7, followed by "other N/A" at 2.0. An alternative interpretation using these exponents is that if a respondent indicates that pesticides are a serious problem (versus the base), the probability of being non-adopter type "never heard" is 15 times less likely than being an adopter, and being "other N/A" is 7 times less likely. The effects are smaller for "know somewhat" and even smaller and less significant for "know well". These results hint at the role of environmental knowledge, in addition to concern, that is highlighted in the organic literature. Households who are more familiar with organic pesticides could more easily transition to being adopters. The fact that those who indicate it is a serious problem are not significantly less likely to not use pesticides than to adopt organic ones implies that at least some people do not use pesticides due to environmental concerns.

For the importance given to neighbors' perceptions of their lawn, if people disagree this is important (versus agree) they are less likely to be in the "know somewhat", "know well", or "other N/A" categories than to be adopters. In other words, adopters put less weight on the opinions of their neighbors than these categories. The lack of adoption by those who care what the neighbors think may relate to the perceived lower effectiveness of organic products, but examining the summary statistics, adopters do not have weedier lawns. The magnitude of the effect for the two non-adopter categories with some knowledge is similar; they are about two times $\left(=\mathrm{e}^{0.8}\right)$ less likely to be adopters. The effect of disagreeing with the statement is the highest for the "other N/A" category. Households who are not using any pesticides are distinct from other non-adopters since the coefficients are positive, and for the neutral response, significant. In other words, if they are neutral, they are more likely to not apply pesticides than to be adopters. This may indicate that they don't care about either their lawn or their neighbors.

The effect of health concerns represented by whether households have child- 
ren under 12 is not significant in this study, although estimated coefficients are positive for every type of non-adopters. This result is unexpected and robust to an alternative specification of dropping a somewhat correlated variable, age. As indicated in the literature review, there are two counteracting effects, health concern and the financial effect of having a larger family. The role of children regarding organic purchases is still not clear in the literature [51].

Gardening behaviors, defined by time spent gardening and use of pest control services, have different effects on adoption. Similar to the results regarding perceived seriousness of environmental problems, those indicating they spent "more than 15 hours" gardening versus the base category of " 6 - 10 hours" were significantly less likely to be in any of the non-adopter categories. In other words, serious gardeners are more likely to use organic pesticides, as expected from the literature. The magnitudes are large: the biggest effect is for "never heard," followed by "no pesticides", "other N/A", "know somewhat", and "know well". Thus, the probability of non-adoption relative to adoption would be from 3 - 5 times less for gardeners spending more than 15 hours a month for lawn care. The probability is smallest for those with the most knowledge and largest for those with the least knowledge. Note that time can be also treated as a substitute input for pesticides in the model proposed by Templeton et al. (1999) [63]. Holding other factors constant, the other gardening behavior, use of pest control services, is not significant in the study.

There is only one type of non-adopter category for which weed density is significant. Households whose lawn has 10 - 40 weeds per square yard (versus less than 10) or simply don't know are more likely to be non-adopters who don't use pesticides rather than being adopters. The results support the hypothesis that not using any pesticides (or not caring) may have allowed the proliferation of weeds, rather than weeds representing a need for effective herbicides/pesticides. The estimates are approximately 0.95 implying the probability of not using any pesticides is 3 times more likely than adoption for those response categories. The effect of "greater than 40 weeds" is not significant which may be partly due to the low number of responses in this category.

Demographic variables do not seem to have much impact on organic pesticide adoption. While the signs for male versus female generally align with the literature, there are no significant effects, ceteris paribus. This result is similar to Shin and McCann [73] for the adoption of watershed conservation practices. Regarding age, compared to those over 60 , those 18 - 30 are more likely to not apply pesticides than to adopt organic ones. They may be new to having a home and yard and starting their careers. The middle-aged category, versus over 60 , is more likely to have never heard of organic pesticides or to not apply any pesticides than to adopt. The probability of being these non-adopter types is about 3 times more likely than being an adopter. In other words, there is some evidence that those over 60 are more likely to adopt.

If a respondent had some college versus a high school diploma or less, they are 
somewhat more likely to be adopters. From Table 3, the significant coefficient estimates are $-1.09,-0.88$, and -1.14 for "know somewhat", "know well", and "other N/A" non-adopters, respectively. That means they are about 3 times less likely to be adopters. These results support studies which imply positive effects of educational level on adoption in the organic literature. However, there are no significant effects for the higher education.

The main reason for the positive effect of income on adoption in the literature is costly new technology or products being more expensive, but that may be not the case for organic pesticides because there are some cheap home-made pesticides such as vinegar. There are few significant income effects. Compared to the base of $\$ 25,000$ - 49,999 , those earning the next larger income are less likely to have never heard of organic pesticides than to be adopters. Those earning the highest income level are generally more likely to adopt, which is in line with the literature. Looking at the table, those who earn more than $\$ 100,000$ (versus the base) are less likely to be the never heard, no pesticides or other N/A types of non-adopters than to adopt. The largest effect is for no pesticides with a coefficient of -1.53 . The probability of being in these categories of non-adopters is 3 4 times less likely than being an adopter.

These regression analyses show that seriousness of environmental concerns, importance of neighbors' opinions, and time spent gardening are important factors affecting the adoption of organic pesticide practices for lawn care. However, contrary to expectations, factors such as having children under 12 and hiring professional pest control services are not significant while the effects of a specific attribute of the lawn like weed density and demographic characteristics are not clear or consistent in this study. We also examine several alternative models to see whether the results are robust to different model specifications.

We tested for multicollearity in two ways. We calculated variance inflation factors (VIFs) for all variables. Since all the VIFs are less than the standard cutoff of 10 , there is no evidence of multicollinearity in the full model. Almost all correlation coefficients were smaller than 0.3 except for age and having children under 12 (0.6). Using a Chi-square test for independence, we find that these two variables are significantly correlated $(\mathrm{p}<0.0001)$.

Based on the correlation between age and children, we ran two reduced models. The first model is defined by excluding the children under-12 variable while the second one leaves the age variable out of the set of explanatory variables. The estimation results of these models are reported in Appendix 1 and Appendix 2, respectively. The results are generally robust regarding signs and significance. More specifically, the children under-12-variable is still not significant after dropping age. For both alternative models, the neutral response regarding neighbors became significant at the $10 \%$ level for the "know somewhat" type of non-respondent, and 0 - 5 hours spent gardening became significant at the $10 \%$ level for the "other N/A" type. When the variable relating to young children was dropped, there were minor changes to the age variables, the 18 - 30 category is 
no longer significant at the $10 \%$ level for those using no pesticides, and the 46 60 age category for "never heard" went from the $10 \%$ to $5 \%$ level of significance.

We consider McFadden's pseudo $\mathrm{R}^{2}$, Nagelkerke's pseudo $\mathrm{R}^{2}$, and information measures like the Akaike information criterion (AIC) and Bayesian information criterion (BIC) to assess which model is a better fit given the dataset. We find that the full model has the largest pseudo R-squared values, followed by the model excluding children and the one excluding age. The smallest AIC and BIC are for the model removing age, followed by the one removing children and the full model. We cannot improve AIC and BIC without reducing the pseudo R-squared values. For consistency with other studies, we prefer using pseudo $\mathrm{R}$-squared to evaluate the models. The full model in Table 3 would be the best in this regard, offering more explanatory power than the other models.

Third, we compare the full model to one keeping all "not applicable" respondents lumped together, rather than separating out those who apparently use no pesticides. The results of this model are reported in Appendix 3. In general, the significant coefficients of the other non-adopter groups ("never heard", "know somewhat", and "know well") are the same in sign and magnitude. The model without identifying those using no pesticides has lower pseudo R-squared values than the full model: $8.4 \%$ vs $10.8 \%$, and $22.4 \%$ vs $30.1 \%$, for the McFadden's and the Nagelkerke's measures, respectively. Also, as indicated by the results of the full model, there are cases where the results of the no pesticide group are opposite to those of the other N/A respondents.

\section{Conclusions, Implications, and Limitations}

The low adoption rate of residential lawn care BMPs such as organic pesticides means that further environmental improvement is possible if we can identify factors that could lead to improved management practices. In this paper, we examine different characteristics of adopters and non-adopters to identify important drivers of organic pesticide adoption. Given the paucity of research on organic practices in residential lawn care, possible determinants are extracted from multiple literatures. Using unique household data from Missouri, the study also distinguishes five distinct non-adopter groups for a deeper understanding of the factors affecting adoption. A standard multinomial logistic regression is employed to test significance of these determinants and explain household behavior regarding organic pesticides.

Overall, the estimation results support most of the hypotheses of the study. Perceived seriousness of environmental problems related to pesticides, low importance of neighbors' opinions of their lawn, and time spent gardening are critical factors since they are significantly different between adopters and most non-adopter groups. On the other hand, having children under 12, which represents health concerns of the household, is not significant, in line with some previous studies [11] [51]. Demographic variables are also not generally significant determinants of organic pesticide adoption, ceteris paribus. Our results can 
provide information for researchers, educational outreach organizations, and policy makers.

The study provides some insights for conducting future adoption studies. The differences in coefficients between non-adopter groups imply that distinguishing non-adopters is more meaningful and appropriate than lumping them together as in traditional adoption studies. This information could enable targeting of educational campaigns. For example, people who were most knowledgeable about the practice were often quite different from those who had never heard of it. Distinct characteristics of non-adopter groups can be useful to evaluate the importance of determinants in different contexts to enable a deeper understanding of the adoption process. For example, providing more information to knowledgeable non-adopters is less likely to be helpful than providing information to first-time homebuyers. Those who use no pesticides for environmental reasons may not be aware of environmentally friendly alternatives. Another innovation was separating out people who seem to not apply any pesticides at all from the "other N/A" group. In some cases, signs and significance differed between these subgroups, which has implications for future studies. However, the remaining not applicable group still represents $16 \%$ of respondents, so future research to further identify reasons for this response may be worthwhile.

There are also implications that flow from some of our key results. First, there are two groups that are low-hanging fruit, people with pro-environmental attitudes and those whose hobby is gardening. The effects of these characteristics are so dominant that these people may be more likely to adopt organic pesticides and other residential BMPs, regardless of other factors. Environmental organizations that focus on unrelated issues, such as climate change, may be targeted for outreach regarding personal behaviors that affect water quality. People who spent more than 10 hours gardening were more likely to be adopters, and this effect was particularly large for those spending over 15 hours per month. This implies that gardening clubs, magazines, and websites may be a good way to reach people who may be predisposed to environmentally friendly practices that may not be particularly convenient. They may also gain utility from trying new gardening practices.

The fact that $24 \%$ of respondents indicate they know the practice well but have not adopted implies that awareness is not the only barrier. This may relate to perceived or actual problems with effectiveness and convenience of current organic pesticides compared to conventional ones or pesticide free solutions. Non-adopters caring more about what the neighbors think may also be related to the effectiveness issue. To address this issue with cleaning products, the Sierra Club collaborated with Clorox to develop a line of environmentally friendly products. Research to develop effective and convenient environmentally friendly products, both commercial and home-made, is needed. Dissemination of information on effective solutions to residents and pest control businesses, including experiences from successful adopters, may increase adoption. Regarding policy, 
a label for organic or environmentally friendly household products, similar the USDA one for food, may be helpful in creating markets for these products.

While similar to other adoption studies, the explanatory power of the model is low. Including barriers related to the practice may be helpful; for example, physical limitations may limit the use of some practices by certain individuals. The heterogeneous characteristics of organic pesticides such as price and convenience are not covered in the study. The cost of home-made organic pesticides is often lower while that of commercial products is typically higher than conventional pesticides. The same holds for convenience; many organic pesticides are ready to use but some of them require preparation time or additional equipment. Including these characteristics as well as perceptions could increase the explanatory power of the model. Additional research to examine gardeners who are not using any pesticides and those who adopt environmentally friendly, but not organic, pesticide management practices may be interesting since the water quality impacts are different from other non-adopters.

\section{Acknowledgements}

This study was partially funded by a USDA-NIFA Integrated Research, Extension and Education 406 Project (Award 2012-03652) and by the Missouri Agricultural Experiment Station.

\section{Conflicts of Interest}

The authors declare no conflicts of interest regarding the publication of this paper.

\section{References}

[1] Cohen, P. (2018) National Gardening Survey, 2018 Edition. https://GardenResearch.com

[2] Adwood, D. and Paisley-Jones, C. (2017) Pesticides Industry Sales and Usage 2008-2012: Market Estimates. U.S. Environmental Protection Agency, Washington DC.

[3] Robbins P. and Sharp J. (2003) The Lawn-Chemical Economy and Its Discontents. Antipode, 35, 955-979. https://doi.org/10.1111/j.1467-8330.2003.00366.x

[4] Marshall, S., Orr, D., Bradley, L. and Moorman, C. (2015) A Review of Organic Lawn Care Practices and Policies in North America and the Implications of Lawn Plant Diversity and Insect Pest Management. HortTechnology, 25, 437-446. https://doi.org/10.21273/HORTTECH.25.4.437

[5] Bahlai, C.A., Xue, Y., McCreary, C.M., Schaafsma, A.W. and Hallett, R.H. (2010) Choosing Organic Pesticides over Synthetic Pesticides May Not Effectively Mitigate Environmental Risk in Soybeans. PLoS ONE, 5, e11250.

https://doi.org/10.1371/journal.pone.0011250

[6] Alumai, A., Salminen, S.O., Richmond D.S., Cardina, J. and Grewal, P.S. (2009) Comparative Evaluation of Aesthetic, Biological, and Economic Effectiveness of Different Lawn Management Programs. Springer Science + Business Media, LLC, Berlin. https://doi.org/10.1007/s11252-008-0073-8 
[7] Levy, N. (2018) Louisiana Urban and Suburban Homeowners' Fertilizer Management Behavioral Beliefs, Intentions, and Past Behaviors. LSU Doctoral Dissertations, Louisiana State University, Baton Rouge, LA, 4687. https://digitalcommons.lsu.edu/gradschool_dissertations/4687

[8] Prokopy, L.S., Floress, K., Klotthor-Weinkauf, D. and Baumgart-Getz, A. (2008) Determinants of Agricultural Best Management Practice Adoption: Evidence from the Literature. Journal of Soil and Water Conservation, 63, 300-311. https://doi.org/10.2489/jswc.63.5.300

[9] Ellis, W.B. and Bradley, M.F. (1996) The Organic Gardener's Handbook of Natural Insect and Disease Control. Rodale Press, Inc., New York.

[10] Asif, M., Xuhui, W., Nasiri, A. and Ayyub, S. (2018) Determinant Factors Influencing Organic Food Purchase Intention and the Moderating Role of Awareness: A Comparative Analysis. Food Quality Preference, 63, 144-150. https://doi.org/10.1016/j.foodqual.2017.08.006

[11] Janssen, M. (2018) Determinants of Organic Food Purchases: Evidence from Household Panel Data. Food Quality and Preference, 68, 19-28. https://doi.org/10.1016/j.foodqual.2018.02.002

[12] Li, J., Zepeda, L. and Gould, B.W. (2007) The Demand for Organic Food in the U.S.: An Empirical Assessment. Journal of Food Distribution Research, 38, 54-69.

[13] Boccaletti, S. and Nardella, M. (2000) Consumer Willingness to Pay for Pesticide-Free Fresh Fruit and Vegetables in Italy. International Food and Agribusiness Management Review, 3, 297-310. https://doi.org/10.1016/S1096-7508(01)00049-0

[14] Bond, C.A., Thilmany, D. and Bond, J.K. (2000) What to Choose? The Value of Label Claims to Fresh Produce Consumers. Journal of Agricultural and Resource Economics, 33, 402-427.

[15] Saba, A. and Messina, F. (2003) Attitudes towards Organic Foods and Risk/Benefit Perception Associated with Pesticides. Food Quality and Preference, 14, 637-645. https://doi.org/10.1016/S0950-3293(02)00188-X

[16] Schäufele, I., Pashkova, D. and Hamm, U. (2018) Which Consumers Opt for Organic Wine and Why? An Analysis of the Attitude-Behaviour Link. British Food Journal, 120, 1901-1914. https://doi.org/10.1108/BFJ-03-2018-0141

[17] Van Doorn, J. and Verhoef, P.C. (2015) Drivers of and Barriers to Organic Purchase Behavior. Journal of Retailing, 91, 436-450. https://www.sciencedirect.com/science/article/abs/pii/S0022435915000184 https://doi.org/10.1016/j.jretai.2015.02.003

[18] Baumgart-Getz, A., Prokopy, L.S. and Floress, K. (2012) Why Farmers Adopt Best Management Practice in the United States: A Meta-Analysis of the Adoption Literature. Journal Environmental Management, 96, 17-25. https://www.sciencedirect.com/science/article/pii/S0301479711003598?via\%3Dihub https://doi.org/10.1016/j.jenvman.2011.10.006

[19] Bach, D. and Rosner, H. (2008) Go Green, Live Rich: 50 Simple Ways to Save the Earth and Get Rich Trying. Broadway Books, New York.

[20] Laferriere, K.A., Crighton, E.J., Baxter, J., Lemyre, L., Masuda, J.R. and Ursitti, F. (2016) Examining Inequities in Children's Environmental Health: Results of a Survey on the Risk Perceptions and Protective Actions of New Mothers. Journal of Risk Research, 19, 271-287.

https://www.tandfonline.com/doi/full/10.1080/13669877.2014.961518

https://doi.org/10.1080/13669877.2014.961518 
[21] Larson, J.L., Dale, A., Held, D., McGraw, B., Richmond, D.S., Wickings, K. and Williamson, R.C. (2017) Optimizing Pest Management Practices to Conserve Pollinators in Turf Landscapes: Current Practices and Future Research Needs. Journal of Integrated Pest Management, 8, No. 1. https://doi.org/10.1093/jipm/pmx012

[22] McCann, L. and Shin, D.W. (2018) Household Use of Composted Manure and Phosphorous-Free Fertilizers: Feeling Good versus Doing Good. Journal of Environmental Protection, 9, 140-157. https://doi.org/10.4236/jep.2018.92011

[23] Morris, J. and Bagby, J. (2008) Measuring Environmental Value for Natural Lawn and Garden Care Practices. The International Journal of Life Cycle Assessment, 13, 226-234. https://doi.org/10.1065/lca2007.07.350

[24] Tukey, P. (2007) The Organic Lawn Care Manual: A Natural, Low-Maintenance System for a Beautiful, Safe Lawn. Storey Publishing, North Adams, MA.

[25] Winterich, K.P., Mittal, V. and William, T.R. (2009) Donation Behavior toward in Groups and Out-Groups: The Role of Gender and Moral Identity. Journal of Consumer Research, 36, 199-214. https://doi.org/10.1086/596720

[26] Veldstra, M.D., Alexander, C.E. and Marshall, M.I. (2014) To Certify or Not to Certify? Separating the Organic Production and Certification Decisions. Food Policy, 49, 429-436. https://doi.org/10.1016/j.foodpol.2014.05.010

[27] Shashi, A.A., Kottala, S.Y. and Singh, R. (2015) A Review of Sustainability, Deterrents, Personal Values, Attitudes and Purchase Intentions in the Organic Food Supply Chain. Pacific Science Review B: Humanities and Social Sciences, 1, 114-123. https://doi.org/10.1016/j.psrb.2016.09.003

[28] Blaine, T.W., Clayton, S., Robbins, P. and Parwinder, G.S. (2012) Homeowner Attitudes and Practices Towards Residential Landscape Management in Ohio, USA. Springer Science + Business Media, LLC, New York. https://doi.org/10.1007/s00267-012-9874-X

[29] Dettmann, R.L. and Dimitri, C. (2009) Who's Buying Organic Vegetables? Demographic Characteristics of U.S. Consumers. Journal of Food Products Marketing, 16, 79-91. https://doi.org/10.1080/10454440903415709

[30] Yadav, R. and Pathak, G. (2016) Young Consumers' Intention towards Buying Green Products in a Developing Nation: Extending the Theory of Planned Behavior. Journal of Cleaner Production, 135, 732-739. https://doi.org/10.1016/j.jclepro.2016.06.120

[31] Brehm, J.M., Pasko, D.K. and Eisenhauer B.W. (2013) Identifying Key Factors in Homeowner's Adoption of Water Quality Best Management Practices. Environmental Management, 52, 113-122. https://doi.org/10.1007/s00267-013-0056-2

[32] Ngobo, P. (2011) What Drives Household Choice of Organic Products in Grocery Stores? Journal of Retailing, 87, 90-100. https://doi.org/10.1016/j.jretai.2010.08.001

[33] Genius, M., Tzouvelekas, V. and Pantzios, C. (2006) Information Acquisition and Adoption of Organic Farming Practices. Journal of Agricultural and Resource Economics, 31, 1-21.

[34] Dreezens, E., Martijin, C., Tenbult, P., Kok, G. and Vries, N.K. (2005) Food and Values: An Examination of Values Underlying Attitudes toward Genetically Modified and Organically Grown Food Products. Appetite, 44, 115-122. https://doi.org/10.1016/j.appet.2004.07.003

[35] Magnusson, M. (2001) Attitudes towards Organic Foods among Swedish Consumers. British Food Journal, 103, 209-226. https://doi.org/10.1108/00070700110386755

[36] Lea, E. and Worsley, T. (2005) Australians' Organic Food Beliefs, Demographics 
and Values. British Food Journal, 107, 855-869.

https://doi.org/10.1108/00070700510629797

[37] Vermeir, I. and Verbeke, W.J. (2006) Sustainable Food Consumption: Exploring the Consumer "Attitude-Behavioral Intention" Gap. Journal of Agricultural and Environmental Ethics, 19, 169-194. https://doi.org/10.1007/s10806-005-5485-3

[38] Moser, K. (2016) Consumers' Purchasing Decisions Regarding Environmentally Friendly Products: An Empirical Analysis of German Consumers. Journal of Retailing and Consumer Services, 31, 389-397. https://doi.org/10.1016/j.jretconser.2016.05.006

[39] Hughner, R.S., McDonagh, P., Prothero, A., Shultz, C.J. and Stanton, J. (2007) Who Are Organic Food Consumers? A Compilation and Review of Why People Purchase Organic Food. Journal of Consumer Behaviour, 6, 94-110. https://doi.org/10.1002/cb.210

[40] Reimer, A.P. and Prokopy, L.S. (2012) Environmental Attitudes and Drift Reduction Behavior among Commercial Pesticide Applicators in a U.S. Agricultural Landscape. Egyptian Journal of Environmental Management, 113, 361-369. https://doi.org/10.1016/j.jenvman.2012.09.009

[41] Riar, A., Mandloi, L.S., Poswal, R.S., Messmer, M.M. and Bhullar, G.S. (2017) A Diagnosis of Biophysical and Socio-Economic Factors Influencing Farmers' Choice to Adopt Organic or Conventional Farming Systems for Cotton Production. Frontiers in plant. Frontiers in Plant Science, 8, 1289. https://doi.org/10.3389/fpls.2017.01289

[42] Beedell, J. and Rehman, T. (2000) Using Social-Psychology Models to Understand Farmers' Conservation Behavior. Journal of Rural Studies, 16, 117-127. https://doi.org/10.1016/S0743-0167(99)00043-1

[43] Grob, A. (1995) A Structural Model of Environmental Attitudes and Behaviour. Journal of Environmental Psychology, 15, 209-220. https://doi.org/10.1016/0272-4944(95)90004-7

[44] Jin, S., Bluemling, B. and Mol, A. (2015) Information, Trust and Pesticide Overuse: Interactions between Retailers and Cotton Farmers in China. Wageningen Journal of Life Sciences, 72, 23-32. https://doi.org/10.1016/j.njas.2014.10.003

[45] Philbert, A., Lyantagaye, S. and Nkwengulila, G. (2014) A Review of Agricultural Pesticides Use and the Selection for Resistance to Insecticides in Malaria Vectors. Advances in Entomology, 2, 120-128. https://doi.org/10.4236/ae.2014.23019

[46] Makatouni, A. (2002) What Motivates Consumers to Buy Organic Food in UK? Results from a Qualitative Study. British Food Journal, 104, 345-352. https://doi.org/10.1108/00070700210425769

[47] Padel, S. and Foster, C. (2005) Exploring the Gap between Attitudes and Behavior: Understanding Why Consumers Buy or Do Not Buy Organic Food. British Food Journal, 107, 606-625. https://doi.org/10.1108/00070700510611002

[48] Singh, Y., Singh, B., Pabbi, S. and Singh, P.K. (2007) Impact of Organic Farming on Yield and Quality of BASMATI Rice and Soil Properties. Scientific Conference on Organic Agriculture, 20, 129-138. https://orgprints.org/9783/

[49] USGS (2000) The United States Geological Survey Report, 1999. U.S. Government Printing Office, Washington DC.

[50] Davis, J.R., Brownson, R.C. and Garcia, R. (1992) Family Pesticide Use in the Home, Garden, Orchard, and Yard. Environment Contamination Toxicology, 22, 260-266. https://doi.org/10.1007/BF00212083

[51] Boizot-Szantai, C., Hamza, O. and Soler, L.G. (2017) Organic Consumption and 
Diet Choice: An Analysis Based on Food Purchase Data in France. Appetite, 117, 17-28. https://doi.org/10.1016/j.appet.2017.06.003

[52] Radman, M. (2005) Consumer Consumption and Perception of Organic Products in Croatia. British Food Journal, 107, 263-273. https://doi.org/10.1108/00070700510589530

[53] Gomiero, T. (2018) Food Quality Assessment in Organic vs. Conventional Agricultural Produce: Findings and Issues. Applied Soil Ecology, 123, 714-728. https://doi.org/10.1016/j.apsoil.2017.10.014

[54] Baker, S., Thompson, K. and Engelken, J. (2004) Mapping the Values Driving Organic Food Choice. European Journal of Marketing, 38, 995-1012. https://doi.org/10.1108/03090560410539131

[55] Huang, C. (1996) Consumer Preferences and Attitudes towards Organically Grown Produce. European Review of Agricultural Economics, 23, 331-342. https://doi.org/10.1093/erae/23.3.331

[56] Lockie, S., Lyons, K., Lawrence, G. and Mummery, K. (2002) Eating Green: Motivations behind Organic Food Consumption in Australia. European Society for Rural Sociology, 41, 23-40. https://doi.org/10.1111/1467-9523.00200

[57] Meehan, T.D., Werling, B.P., Landis, D.A. and Gratton, C. (2011) Agricultural Landscape Simplification and Insecticide Use in the Midwestern United States. Proceedings of the National Academy of Sciences of the United States of America, 108, 11500-11505. https://doi.org/10.1073/pnas.1100751108

[58] Nassauer, J.I., Wang, Z. and Dayrell, E. (2009) What Will the Neighbors Think? Cultural Norms and Ecological Design. Landscape and Urban Planning, 9, 282-292. https://doi.org/10.1016/j.landurbplan.2009.05.010

[59] Gudade, B.A., Chhetri, P., Gupta, U., Deka, T.N., Vijayan, A.K. and Bhattarai, N.K. (2014) The Study of Ecofriendly Practices of Large Cardamom Cultivation in Sikkim and Darjeeling. Ecology, Environment and Conservation, 20, 119-123.

[60] Jolly, D. (1991) Differences between Buyers and Non-Buyers Of Organic Produce and Willingness to Pay Organic Price Premiums. Journal of Agribusiness, 9, 1-15.

[61] Greene, C. and Kremen, A. (2003) US Organic Farming in 2000-2001: Adoption of Certified Systems. United States Department of Agriculture, Washington DC.

[62] Constance, D.H. and Choi, J.Y. (2010) Overcoming the Barriers to Organic Adoption in the United States: A Look at Pragmatic Conventional Producers in Texas. Sustainability, 2, 163-188. https://doi.org/10.3390/su2010163

[63] Templeton, S., Yoo, S. and Zilberman, D. (1999) An Economic Analysis of Yard Care and Synthetic Chemical Use: The Case of San Francisco. Environmental and Resource Economics, 14, 385-397. https://doi.org/10.1023/A:1008323827326

[64] Rogers, E. (2010) Diffusion of Innovations. 5th Edition, Simon and Schuster, New York.

[65] Straub, E. (2009) Understanding Technology Adoption: Theory and Future Directions for Informal Learning. Review of Educational Research, 79, 625-649. https://doi.org/10.3102/0034654308325896

[66] McFadden, D. (1974) Conditional Logit Analysis of Qualitative Choice Behavior. In: Frontiers in Econometric, Academic Press, New York, 105-142.

[67] Luce, R. (1959) Individual Choice Behaviour: A Theoretical Analysis. John Wiley \& Sons, New York.

[68] McFadden, D. and Train, K. (2000) Mixed MNL Models for Discrete Response. Journal of Applied Econometrics, 15, 447-470. 
https://doi.org/10.1002/1099-1255(200009/10)15:5<447::AID-JAE570>3.0.CO;2-1

[69] Small, K.A. and Rosen, H.S. (1981) Applied Welfare Economics with Discrete Choice Models. Econometrica, 49, 105-130. https://doi.org/10.2307/1911129

[70] Ben-Akiva, M.E. and Lerman, S.R. (1985) Discrete Choice Analysis: Theory and Application to Travel Demand. MIT Press, Cambridge, MA.

[71] McFadden, D. (1981) Econometric Models of Probabilistic Choice. In: Structural Analysis of Discrete Data: With Econometric Applications, MIT Press, Cambridge, MA, 198-272.

[72] Lichtenberg, E. (2004) Cost-Responsiveness of Conservation Practice Adoption: A Revealed Preference Approach. Journal of Agricultural and Resource Economics, 29, 420-435.

[73] Shin, D.W. and McCann, L. (2018) Enhancing Adoption Studies: The Case of Residential Stormwater Management Practices in the Midwest. Agricultural and Resource Economics Review, 47, 32-65. https://doi.org/10.1017/age.2017.3 


\section{Appendix}

Appendix 1. Estimation results of the reduced "child factor" model (base: adopters).

\begin{tabular}{lll}
\hline & \multicolumn{2}{c}{ Non-Adopters } \\
\cline { 2 - 3 } Independent Variables (Factors) & Never heard $\quad$ Know somewhat Know well No Pesticides Other N/A
\end{tabular}

Personal attitude measures

Environmental concerns (base: Not or slight problem)

Moderate problem

Serious problem

Don't know

Neighbors' opinion important (base: Agree)

Disagree

Neutral

\section{Gardening behaviors}

Monthly hours spent gardening (base: 6 - 10 hours)

0 - 5 hours

0.718

$11-15$ hours

More than 15 hours

\section{Pest control services hired (base: No)}

Use service

0.0002

\section{$\underline{\text { Lawn attributes }}$}

Number of weeds per square yard (base: $<10$ weeds)

10 - 40 weeds

0.284

More than 40 weeds

Don't know

$-15.80$

0.703

Demographic characteristics

\section{Male}

Age (base: $>60$ years)

18 - 30 years

31 - 45 years

46 - 60 years

\section{Education (base: High school or less)}

Some college or 2-year college

4-year college

Post-graduate

0.549

1.047

0.464

$1.108^{* *}$

$-0.464$

$-0.100$

$-0.126$

Household income (base: $\$ 25,000$ - \$49,999)

$<\$ 24,999$

$\$ 50,000$ - $\$ 74,999$

$\$ 75,000$ - $\$ 99,999$

DOI: 10.4236/jep.2020.114016

$\begin{array}{lll}-0.835^{*} & -1.416^{* *} & -1.497^{* * *} \\ -0.841^{*} & -0.820 & -2.042^{* * *} \\ -0.403 & -0.031 & -0.708\end{array}$

$-0.668$

$-0.769^{* *}$

0.756

$-1.135$

$-0.638^{\star *}$

$1.030^{*}$

$-0.826^{\star *}$ 


\section{Continued}

\begin{tabular}{|c|c|c|c|c|c|}
\hline$>\$ 100,000$ & $-1.308^{*}$ & -0.168 & 0.068 & $-1.461^{\star \star}$ & $-1.083^{* *}$ \\
\hline Constant & 0.365 & $2.092^{* * *}$ & $2.164^{* * *}$ & -0.519 & $2.787^{* * *}$ \\
\hline \multicolumn{6}{|l|}{ Goodness-of-fit } \\
\hline $\mathrm{N}$ & & & 661 & & \\
\hline LR Chisquare (120) & & & 235.07 & & \\
\hline $\operatorname{Pr}(>$ Chisquare $)$ & & & $2.942 \mathrm{e}-10^{\star * *}$ & & \\
\hline AIC & & & 2199.871 & & \\
\hline $\mathrm{AICc}$ & & & 2253.648 & & \\
\hline BIC & & & 2739.121 & & \\
\hline McFadden's Pseudo R ${ }^{2}$ & & & $10.7 \%$ & & \\
\hline Cox \& Snell Pseudo's R ${ }^{2}$ & & & $29.9 \%$ & & \\
\hline Nagelkerke's Pseudo $\mathrm{R}^{2}$ & & & $29.9 \%$ & & \\
\hline
\end{tabular}

Notes: Superscripts ${ }^{*},{ }^{* *}$ and ${ }^{* *}$ indicate statistical significance at the 10 percent, 5 percent and 1 percent levels, respectively.

Appendix 2. Estimation results of the reduced "Age Factor" model (base: adopters).

\begin{tabular}{lll}
\hline \multirow{2}{*}{ Independent Variables (Factors) } & \multicolumn{2}{c}{ Non-Adopters } \\
\cline { 2 - 3 } & Never heard $\quad$ Know somewhat $\quad$ Know well No Pesticides Other N/A
\end{tabular}

Personal attitude measures

Environmental concerns (base: Not or slight problem)

Moderate problem

Serious problem

Don't know

Neighbors' opinions important (base: Agree)

Disagree

Neutral

Having children under 12 (base: No children)

At least 1 child

0.359

$-1.364^{\star *}$
$-2.689^{\star * *}$
-0.279

$-0.830$

$-0.252$

$$
-0.756^{\star *}
$$

$-0.510^{*}$

$-0.762$

$-0.622^{\star *}$

$1.040^{*}$

$-1.110^{\star * *}$

Gardening behaviors

Monthly hours spent gardening (base: 6 - 10 hours)
0 - 5 hours
$11-15$ hours

More than 15 hours

\section{Pest control services hired (base: No)}

Use service

$$
0.708
$$$$
0.343
$$

$-1.066^{* *}$

$-1.610^{* * *}$

$-0.594^{\star *}$

$-1.278^{* * *}$

0.210

0.416

$-0.060$
$-0.105$

$-0.166$

$-0.410$

$-16.383$

0.133

\section{$\underline{\text { Lawn attributes }}$}

Number of weeds per square yard (base: $<10$ weeds)

10 - 40 weeds

0.264

0.538

0.276

$1.042^{* *}$

0.133 


\section{Continued}

More than 40 weeds

Don't know

Demographic characteristics

Male

Education (base: High school or less)

Some college or 2-year college

4-year college

Post-graduate

Household income (base: \$25,000 - \$49,999)

$<\$ 24,999$

$\$ 50,000$ - $\$ 74,999$

$\$ 75,000$ - $\$ 99,999$

$>\$ 100,000$

Constant

Goodness-of-fit

$\mathrm{N}$

LR Chisquare (120)

$\operatorname{Pr}(>$ Chisquare $)$

AIC

$\mathrm{AICc}$

BIC

McFadden's Pseudo $\mathrm{R}^{2}$

Cox \& Snell Pseudo's $\mathrm{R}^{2}$

Nagelkerke's Pseudo $R^{2}$
$-15.737$

0.652

0.474

$-0.351$

$-0.123$

$-0.189$

0.726

$-1.118^{\star}$

0.128

$-1.110$

0.873
0.733

0.444

0.383

$-1.000^{*}$

$-0.358$

$-0.615$

$-0.554$

0.113

0.426

$-0.879^{*}$

$-0.605$

$-0.769$

$-0.002$

$-0.127$

0.373

$-0.110$

$2.303^{* * *}$

.273

$-0.056$

0.294

0.019

$2.155^{\star \star *}$
$-1.186$

0.402

0.392

0.305

$-0.392$

$-1.027^{*}$

$-0.655$

$-0.529$

0.061

0.413

$-0.286$

$-0.519$

$-0.530$

$-0.131$

$-0.430$

$-1.462^{*}$

$-0.998^{*}$

$-0.037$

$3.015^{* * *}$

Notes: Superscripts ${ }^{*},{ }^{*}$ and ${ }^{* *}$ indicate statistical significance at the 10 percent, 5 percent and 1 percent levels, respectively.

Appendix 3. Estimation results of the model without identification of "not applicable" (base: adopters).

\begin{tabular}{|c|c|c|c|c|}
\hline \multirow{2}{*}{ Independent Variables (Factors) } & \multicolumn{4}{|c|}{ Non-Adopters } \\
\hline & Never heard & Know somewhat & Know well & Not Applicable \\
\hline \multicolumn{5}{|l|}{ Personal attitude measures } \\
\hline \multicolumn{5}{|c|}{ Environmental concerns (base: Not or slight problem) } \\
\hline Moderate problem & $-1.375^{\star *}$ & $-0.980^{\star *}$ & $-0.837^{\star}$ & $-1.517^{\star \star *}$ \\
\hline Serious problem & $-2.724^{* * *}$ & $-1.230^{* * *}$ & $-0.842^{*}$ & $-1.625^{\star * *}$ \\
\hline Don’t know & -0.310 & -0.663 & -0.398 & -0.571 \\
\hline \multicolumn{5}{|c|}{ Neighbors' opinions important (base: Agree) } \\
\hline Disagree & -0.908 & $-0.788^{* *}$ & $-0.773^{* *}$ & $-0.665^{*}$ \\
\hline Neutral & -0.209 & -0.509 & $-0.638^{* *}$ & -0.405 \\
\hline \multicolumn{5}{|c|}{ Having children under 12 (base: No children) } \\
\hline At least 1 child & 0.488 & 0.096 & 0.188 & 0.112 \\
\hline
\end{tabular}




\section{Continued}

\section{Gardening behaviors}

Monthly hours spent gardening (base: 6 - 10 hours)

0 - 5 hours

$11-15$ hours

More than 15 hours

Pest control services hired (base: No)

Use service

\section{Lawn attributes}

Number of weeds per square yard (base: $<10$ weeds)

10 - 40 weeds

More than 40 weeds

Don't know

\section{Demographic characteristics}

\section{Male}

Age (base: $>60$ years)

18 - 30 years

31 - 45 years

46 - 60 years

Some college or 2-year college

4-year college

Post-graduate

$\$ 50,000$ - $\$ 74,999$

$\$ 75,000$ - $\$ 99,999$

$>\$ 100,000$

Constant

\section{Goodness-of-fit}

$\mathrm{N}$

LR Chisquare (96)

0.319

$-13.424$

0.713

0.540

0.946

0.156

$1.058^{\star}$

$-0.517$

$-0.128$

$-0.158$

0.818

$-1.215^{*}$

0.033

$-1.362^{*}$

0.424
Education (base: High school or less)

Household income (base: $\$ 25,000$ - $\$ 49,999$ )

$<\$ 24,999$

0.504

0.706

0.463

0.434

0.432

0.143

\subsection{6}

0.157

$1.050^{*}$

0.195

0.027

0.161

0.437

$-0.055$

$0.615^{*}$

$\operatorname{Pr}(>$ Chisquare $)$

AIC

AICc

BIC

McFadden's Pseudo $\mathrm{R}^{2}$

Cox \& Snell Pseudo's $\mathrm{R}^{2}$

Nagelkerke's Pseudo ${ }^{2}$
661

167.54

8.624e-06

2022.232

2058.404

2471.707

$8.4 \%$

$22.4 \%$

$22.4 \%$

Notes: Superscripts ${ }^{*},{ }^{*}$ and ${ }^{* * *}$ indicate statistical significance at the 10 percent, 5 percent and 1 percent levels, respectively. 